\title{
ATUAÇĀO DO ENFERMEIRO NO CONTROLE EPIDEMIOLÓGICO DA HANSENÍASE *
}

\author{
Sara Augusta dos Santos **
}

\begin{abstract}
RESUMO - Analisou-se
seníase, na Seção de Dermatologia Sanitária do Hospital Universitário Pedro Ernesto, UERJ. Pretendeu-se alcançar três objetivos entre eles comparar a qualidade do controle epidemiológico dos casos novos de hanseniase em registro ativo de 1986, com os mesmos casos relativos ao período de 1987. Aplicou-se o método descritivo e análise de documentos dos prontuários desses clientes. Utilizou-se um formulário com questões de múltipla escolha e preenchimento de claros, totalizando 27 itens. Constatou-se que o enfermeiro interfere nas variáveis: exames para firmar diagnóstico, exames de contatos e educação para saúde, contribuindo para a melhoria da qualidade assistencial do hanseniano. Conclui-se que há diferença significativa na qualidade do controle epidemiológico da hanseníase entre os grupos constituídos.
\end{abstract}

ABSTRACT - The question of epidemiolgy quality of hanseniasis in the sanitary dermatology section at Hospital Pedro Ernesto, UERJ have been analysed. It has been intended to achieve 3 objectives among them to compare epidemiologyc control quality of new cases referred in 1987. Descriptive method and an

sheet with multiple choice questions and clear filling have been used with 27 items. It has been observed that the nurse interferes on the variables: exams to firm diagnosis, touch exams and health education, contributing to the hansenian assistential quality improvement. It has been concluded that there has been a significant difference on hanseniasis epidemiologic control quality. Also, it has been concluded that there has been a significant difference of that control quality on constituted group.

\section{INTRODUÇĀO}

O controle da hanseníase já expressa uma área problemática pois, falar em qualidade do controle epidemiológico dessa doença parece envolver outro problema. Entretanto, se os indicadores desse controle são utilizados, há como avaliar sua qualidade ou, então, se fôr estabelecido um critério de avaliação das variáveis do controle epidemiológico torna-se realidade a avaliação dessa qualidade.

Tendo em vista a recente experiência da autora, contribuindo na reorganização da Seção de Dermatologia Sanitária do Serviço de Dermatologia do Hospital Universitário Pedro Emesto
(HUPE, UERJ) e as dificuldades da seção que serve de campo de estágio aos acadêmicos do Curso de Graduação em Enfermagem da Faculdade da UERJ, escolheu-se como situação problema e qualidade do controle epidemiológico de casos novos, em registro ativo, de hanseníase.

Assim, pretendeu-se investigar a seguinte questão:

- Qual é a qualidade do controle epidemiológico dos casos novos de hanseníase, em registro ativo em 1986, "comparado aos casos novos em registro ativo em $1987 ?$

Brinelb da Tese de Livre Docincia em Enfermagem de Saúde Pública. Faculdade de Enfermagem - UERJ.

* Proficor Adjunto. Faculdade de Enfermagem da UERJ. 


\section{DESENVOLVIMENTO DO ESTUDO}

Haja vista que a Seção de Dermatologia Sanitária do HUPE-UERJ possuindo uma população de 835 clientes inscritos com hansenfase, selecionou-se duas amostras (Grupo I e Grupo II), nāo equivalentes sob o ponto de vista de rendomicidade. Considerando-se como variáveis independentes a característica de registro ativo, e caso novo em 1986 e 1987 e a modalidade de tratamento aplicado nesses clientes.

Sendo considerado, controle epidemiologico da hanseníase - procedência do cliente, exames e testes realizados, resultados do exame clínico dermato-neurológico, resultados do exame bacteriológico e do teste de Mitsuda, forma clínica da doença, incapacidade observada na primeira consulta, local da incapacidade, constelação familiar, classificação do contato, vigilância do contato, intervenção terapêutica relacionada à educação para a saúde, esquema terapêutico espacífico, tratamento anterior e prevenção terciária, as variáveis dependentes.

O grupo I correspondeu aos 73 clientes inscritos no ano de 1986 e o grupo II correspondeu aos 86 clientes inscritos no perfodo de janeiro a 20 de novembro de 1987.

Observou-se que a maioria dos clientes de ambos os grupos do estudo teve como procedência a demanda espontânea, seguida de notifícação. Essa deteç̧ão precoce de casos de hanseníase visa aos efeitos terapêuticos, conforme recomenda SANTOS ${ }^{7}$.

Alerta-se, ainda, para o controle do comunicante, ou seja, o exame dos contatos.

A maioria dos clientes apresentou alteraçōes cutâneas e do tronco nervoso, seguida de apenas alterações cutâneas, o que segundo BELDA $^{2}$ pode caracterizar a doença.

A maioria realizou os exames baciloscópio, histológico e o teste de Mitsuda. As provas complementares de histamina e pilocarpina foram aplicadas cada uma em apenas um paciente.

No teste Mitsuda predominou o resultado negativo tanto para o grupo I como para o Grupo II nas formas $\mathrm{V}$ e $\mathrm{D}$. Na forma $\mathrm{T}$ a predominância recaiu sobre o resultado negativo para ambos os grupos. A forma I apresentou tanto resultados positivo quanto negativo em ambos os grupos de estudo.

Confirma-se neste caso, ROTBERG, citado por AZULAI', o resultado negativo é comum nas formas $\mathrm{V}, \mathrm{D}$ e $\mathrm{T}$, e o positivo nas formas I e T. O teste Mitsuda é positivo na maioria da população em geral e significa que as pessoas têm resistência natural ao bacilo de Hansen. $\mathrm{O}$ restante da população que apresenta o resultado negativo representa a margem anérgica de pessoas susceptiveis à forma V, principalmente.

Considerando as formas clínicas, houve semelhança de resultados entre o grupo I e o grupo II. Predominaram as formas $\mathrm{V}$ e D, seguidas da forma $\mathrm{T}$ e a minoria revelou a forma I.

Foram observadas a presença de incapacidade em $15(20,55 \%)$ clientes do grupo I e 19 $(22,10 \%)$ do grupo II. A ausência de incapacidade foi registrada na minoria dos casos de ambos os grupos.

Como a maicria dos sujeitos investigados não teve registrada a incapacidade observada, a sua localização também foi prejudicada. Entretanto houve registro ile incapacidade da mão, pé, mão e pé, mão e olho, nariz e face.

De acordo com OF'ROMOLLA ${ }^{5}$ as alterações neurológicas predominam nos membros inferiores conduzindo à perdas graves da sensibilidade e da capacidade motora. CRISTOFOLINI $^{3}$ chama a atenção para o grande potencial incapacitante físico, social e psicológico da hanseníase reforçando a gravidade das localizações da incapacidade nos membros superiores e inferiores, olho, nariz e face.

\section{CONCLUSĀO}

A situação de controle dos clientes com hanseniase demonstra que estavam sob controle os $73(100 \%)$ clientes do Grupo I e os 86 (100\%) do Grupo II. Estavam sem controle 19 dos matriculados em 1986 e 13 dos matriculados em 1987. Houve um total.de transferências e 3 óbitos dos clientes registrados em 1986 e 1987.

Ainda o estudo revela a existência da média de 148 contatos do Grupo I e da média de 200 contatos do Grupo II sem controle.

Está evidenciada a predominância de clientes e contatos sem controle, que deixaram de receber a assistência à saúde a que têm direito, com cidadãos. Por outro lado a Portaria no 01 de 09/10/1987 do MINISTÉRIO DA SAÚDE“ assegura a essas pessoas o direito à prevenção e o tratamento da hanseníase.

Confirmando PASSOS ${ }^{6}$ a operacionalização do controle da hanseníase ainda deixa a desejar, pois muitos preceitos legais deixam de ser cumpridos, inclusive na assistência de enfermagem.

Sendo a hansenfase uma doença de notificação compulsória é obrigatória a investigação epidemiológica do caso suspeito visando à descoberta da fonte de infecção. Sem o controle do caso suspeito torna-se impossivel a investigação epidemiológica e, portanto, a quebra do elo da cadeia de transmissibilidade.

A falta de controle na hanseníase dificulta a prestação de uma assistência à saúde eficaz, segura e livre de riscos.

Observou-se que somente os 19 pacientes do Grupo I e os 26 do Grupo II que foram orientados pela equipe de enfermagem receboram todas as informaçöes dos temas de edu- 
cação para a saúde. Destaca-se o "tema importância do tratamento", que foi ministrado a todos os clientes. Outro destaque foi o tema "falsos conceitos", que foi debatido com a maioria dos clientes de ambos os grupos.

A educação para a saúde envolve a aceitação ou rejeição de novas informações e valores que estão relacionados com a sua incorporação à nova conduta. É um processo longo que implica também numa relação de confiança e segurança do cliente com o profissional de saúde; é de grande relevância, para assegurar a eficácia das açōes de saúde no que se refere à participação do cliente e seus familiares, ressaltando-se a relevância do autocuidado na área da prevenção da hanseníase.

O enfermeiro deve estimular a participação dos clientes no programa de educação para a saúde para alcançar melhores condições de bem-estar, respeitando as suas decisões; pois o processo não deve ser prescritivo, mas participativo, oferecendo oportunidade para a troca de experiências, discussão dos problemas e valores implícitos na vida do cliente e de seus familiares.

Alerta-se para a importância da educação para a saúde na prevenção e no tratamento das incapacidades, envolvendo não só a equipe de enfermagem mas toda a equipe de saúde.

A educação para a saúde deve assegurar ao paciente o conhecimento indispensável sobre a hanseníase para que modifique suas atitudes e ações visando à prevenção das incapacidades.

A maioria dos pacientes de ambos os grupos de estudo recebe o Esquema 1 preconizado pela Divisão Nacional de Dermatologia Sanitária e os demais recebem o Esquema 2, também, recomendado por essa mesma Divisão, através da Portaria Ministeral no 01 de 09/10/1987.

O Esquema 1 é indicado para os clientes multibacilares, portadores das formas V, D e I quando apresentam o teste de Mitsuda negativo. Esse esquema compreende duas fases. A primeira tem a duração de três meses e inclui os medicamentos Rifampicina na dosagem de 600 $\mathrm{mg}$ por dia e Sulfona, $100 \mathrm{mg}$ diários. A segunda fase inicia-se no 4\% mês de tratamento e só é administrada sulfona na dosagem de $100 \mathrm{mg}$ diárias. A duração deste esquema é de cinco anos após a inativação baciloscópia e na clínica o paciente deve ser mantido sob controle por mais cinco anos.

O Esquema 2 prevê apenas a administração de sulfona, na dosagem de $100 \mathrm{mg}$ diárias, para os clientes paucibacilares, portadores das formas T e I com resultado de Teste Mitsuda positivo. O tratamento deve ser seguido por dois anos, se houver a inativação clínica o cliente $e$ mantido em vigilância, porém sem tratamento, pelo período de dois anos.
Considerando o tratamento de incapacidade, em ambos os grupos de estudos, a maioria dos clientes não teve esse registro em seus prontuários. Nos restantes, a técnica simples sobressai como a mais aplicada, seguida do encaminhamento à Fisioterapia. Os demais foram encaminhados à Neurologia, à Cirurgia Ortopédica e outros, correspondendo ao tratamento que visa a limitação do dano.

Evidencia-se a importância do trabalho multidisciplinar na área da saúde visando à prevenção de incapacidade causada pela hanseníase.

Ressalta-se que a enfermagem deve desenvolver técnicas simples de prevenção e tratamento de incapacidades físicas, em ambulatórios e que podem ser desenvolvidas como autocuidado pelo cliente em seu domicńlio, tais como:

- hidratação e lubrificação da pele

- massagens

- exercícios ativos e passivos

- uso de instrumentos adaptados de trabalho e da vida diária

- uso de calçados adaptados

- proteção de olhos e nariz.

A educação para a saúde deve ser utilizada como estratégia para garantir a eficácia dessas medidas (Ver portaria no 01/10/87/MS).

$\mathrm{Na}$ assistência ao cliente com hansenfase é preciso não descuidar das medidas de higiene, cuidados específicos com o corpo, promoção de conforto e bem-estar físico, mental e social. A assistência de enfermagem deve ser centrada na relação-de-ajuda, isto $\epsilon$, estar presente nas atividades diárias oferecendo apoio, visando ao ajustamento do cliente; $\varepsilon$ um recurso facilitador de mudanças na vida de cada ser.

Essa relação favorece um clima que estimula o cliente a enfrentar os desafios que se antepõem à sua vida diária.

Para conseguir a eficiência destas atividades o enfermeiro precisa ser capaz de reconhecer quando suas ações e reações ajudam ou não o cliente, fazendo-o identificar as suas limitaçōes e tornando-o participante da transformação de sua realidade.

Quanto aos indicadores mencionados, a proporção de menores de 15 anos, os casos novos, $6,8 \%$ no Grupo I e $1,1 \%$ no Grupo II, indicam a tendência decrescente da endemia, comparando-se o primeiro que se refere a 1986 e o segundo a 1987; esse indicador foi considerado médio para o Grupo I e baixo para o Grupo II.

A proporção de casos novos de forma $T$, em relação aos casos novos $V, D$ e $T$, indicou um resultado alto em 1986 e médio em 1987. Comparando ambos os resultados verifica-se a tendência decrescente da endemia.

A proporção de casos novos $\mathrm{V}$ e $\mathrm{D}$ com baciloscopia positiva, apontou um aumento dos indicadores de 1986 para 1987. Esse indicador 
determina a eficácia do tratamento quimiotera pico entre os casos novos. Como houve casos de clientes que não realizaram esses exames o resultado desse indicador está prejudicado. Assim mesmo é significativa a diferença desses indicadores, pois $\mathrm{\epsilon m} 1986$ apresentou valor igual a $32,00 \%$ e em 1987 revelou $54,00 \%$.

A proporção de doentes atendidos diminui de 1986 para 1987, haja vista que os indicadores alcançaram $30,00 \%$ e $2,20 \%$, respectivamente, demonstrando um decréscimo de capacidade do ambulatório no atendimento da clientela em 1987. Deve ser ressaltado que no final de 1987, nos meses de novembro e dezembro, o ambulatório do HUPE esteve fechado devido a greve trabalhista na UERJ, o que favoreceu o decréscimo do atendimento.

Entretanto, revela-se que houve aumento da proporçāo de doentes assíduos, de $32,00 \%$ em 1986 para 39,00\% em 1987.

Considerando o critério de avaliação proposto, nesta pesquísa, e a especificação que 19 clientes do Grupo I e 26 clientes do Grupo II que obtiveram as notas máximas (10 pontos) foram orientados pelo enfermeiro em consulta de enfermagem, deduz-se que houve uma interferência positiva na qualidade do controle epidemiológico, pois esses pacientes contribuiram para a elevação da média obtida pelos grupos de estudo, após a aplicação do referido critério de avaliação.

Assim, conclui-se que há diferença significativa na qualidade do controle epidemiológico da hanseníase, entre o Grupo I e o Grupo II, constituídos por casos novos, em registro ativo, nos períodos de 1986 e 1987, respectivamente.

\section{REFERÊNCIAS BIBLIOGRÅFICAS}

1 AZULAI, R.D. Imunologia. In: Dermatologia Tropical HANSENOLOGIA. Manaus: Calderaro. Funcomiz, 1984.

2 BELDA, Walter. Aspectos da Hansenfase do Município de São Paulo. Rev. Hansenologia Internationalis, São Paulo, 6 (1): 23-50, dez., 1981 .

3 CRIS TOFOLINI, L., AXCAR, S.R., BIZ, L.P.; VIE TH, H. A Enfermagem na Prevençäo e Tratomento dos Comprometimentos Oculares na Hansenfase. Bauru, 1983.

4 MINIS TÉRIO DA SAÚDE. S.NABS/Divisão Nacional de Dermatologia Sanitaria Guia para Controle da Hanseníase, 2 ed. Centro de Documentaçäo, Bras̊ia, 1984.
5 OPROMOLLA, D.V.A. As incapacidades na Hansenfase. In: Noçöes de Hansenfase. (Parte I), Hospital Lauro de Souza Lima. São Paulo, 1981.

6 PASSOS, J.P. Formas de Intervençäo do Enfermeio no Atendimento das Necesridades do Hanseriano. Dissertaçäo (Mestrado em Enfermagem) - Escola de Enfermagem Alfredo Pinto, Universidade do Rio de Janeiro, UNI-RIO, 1985.

7 SAN TOS, Sara Augusta Proposta de um Modelo de Intervençäo do Enfermeiro nos Programas de Infecçōes Respiratórias Agudas. Enfogue centrado em menores de cinco anos. Dissertaçāo (Mestrado em Enfermagem) Escola de Enfermagem Alfredo Pinto, Universidade do Rio de Janeiro, UNI-RIO, 1985. 